\title{
Desencadeamento na neurose e sua relação com o sinthoma e a função do analista no contexto da clínica na atualidade*1
}

\section{The concept of triggering in neurosis and its relationship with sinthome and the role of the psychoanalyst in the context of current clinical psychology}

Este trabalho aborda a noção de desencadeamento nas neuroses, considerando a clínica atual e, para isto, perpassa pela noção de encadeamento e desencadeamento considerando ensinamentos freudiano e lacaniano. Formalizações sobre sinthoma, como elemento que repara os erros do enlaçamento e índice de encadeamento, e sintoma, são convocadas para a conversa em que a neurose, mesmo no contexto da clínica, apresenta-se frequentemente em sua forma não desencadeada. A função do analista como perturbador da defesa e do sinthoma é, assim, questão que se coloca em cena.

Palavras-chave: Desencadeamento, neurose, sinthoma, analista

*1 Artigo derivado de parte da dissertação de mestrado em Psicologia, intitulada Sinthoma e desencadeamento: um estudo sobre o desencadeamento na neurose a partir da histeria rígida e da neurose ordinária, orientada pela profa. dra. Ilka Franco Ferrari, junto à Pontifícia Universidade Católica de Minas Gerais - PUC-Minas.

*2 Centro de Atenção Diária e Integral em Saúde Mental do Ipsemg (Belo Horizonte, MG, Brasil).

*3 Pontifícia Universidade Católica de Minas Gerais - PUC-Minas (Belo Horizonte, MG, Brasil). 


\section{ARTIGOS}

No compasso daquilo que em psicanálise se chama de declínio do viril, do Nome-do-Pai, e a consequente ascensão do objeto $a$ ao zênite social, a prática clínica escancarou aumento de casos para os quais não se encontram os elementos precisos e definidores de uma psicose. Tal fato motivou a realização de três grandes reuniões clínicas conhecidas como Conciábulo de Angers (Miller et al., 1996/1999), Conversação de Arcachon (Miller et al., 1997/1999) e Convenção de Antibes (Miller et al., 1998/2012), no intuito de discussão desses casos que desafiavam a referência diagnóstica existente até então. Surge daí o que se passou a denominar psicoses ordinárias, termo sob responsabilidade de Miller (1998/2012), nas quais estão localizadas psicoses compensadas, suplementadas, tratadas e, inclusive, não desencadeadas, muitas vezes com vestimentas neuróticas. Nesse contexto, surgiram também formalizações sobre a generalização da psicose, todos loucos, ou seja, delirantes e a exigência de afinação do conceito de neurose.

Apesar de Miller destacar que as neuroses têm uma estrutura muito precisa, sabe-se que mudanças ocorridas no último ensino lacaniano, a exemplo da pluralização do Nome-do-Pai e a introdução dos nós borromeanos, impactaram também o campo das neuroses. Tornou-se necessário pensá-las para além do Édipo e o próprio Lacan (1975-76/2007) já dizia de neuroses que não se apresentam com seus sintomas clássicos, em suas considerações acerca da histeria rígida cuja principal característica é não se sustentar pelo amor ao pai, aquele que deve dar sentido ao seu sintoma. $\mathrm{Na}$ atualidade, Schejtman (2013) vem trabalhando a noção de neurose ordinária, em analogia às psicoses assim adjetivadas, considerando que as neuroses também podem se apresentar de forma não desencadeada. Formalizações relevantes para se pensar mudanças evidentes nas formas de apresentação da neurose no contexto clínico.

Um leitor cuidadoso, no entanto, percebe que a noção de desencadeamento na neurose perpassa boa parte da obra de Freud. Em todos os seus casos clínicos ele se empenha em construir a 
história do paciente em torno do momento em que ele adoece. Ele concebe a neurose mais como uma nosologia e, assim, que o sujeito se torna neurótico a partir de determinados acontecimentos. Lacan, por sua vez, constrói uma teoria do desencadeamento da psicose, nos anos 1950, e o localiza naquilo que define como encruzilhada dramática, momento em que o sujeito se vê diante de uma pergunta que não pode responder. Nesse caso o desencadeamento se concretiza pelo retorno, no real, do que foi abolido no simbólico, pela ausência do Nome-do-Pai. E essa formalização, como tem pensado psicanalistas, a exemplo de Leibson (2012) e Schejtman (2013), permite conceber o desencadeamento da neurose também como momento de impossibilidade de resposta, isto é, compreendê-lo como uma ruptura, um encontro com algo incompreensível. Com a introdução dos nós borromeanos, nos anos 1970, o desencadeamento se constitui como o desenlaçamento do nó, tanto para neurose quanto para a psicose.

Leibson (2012) é um dos profissionais que sustenta que o desencadeamento das neuroses é um fato clínico, desde os casos de Freud. Para ele o desencadeamento não se reduz ao mal funcionamento do corpo, a uma mudança do mundo externo ou a uma instabilidade da vida amorosa que 358 provoca sofrimento ao sujeito. Trata-se, fundamentalmente, da formulação de uma pergunta que tem consequências para o sujeito, diz respeito à maneira pela qual se instala um conflito em que o sujeito está envolvido, embora não tenha ideia de como isso se deu. Resume-se a um encontro com algo incompreensível e inevitável.

Há em Freud, portanto, a existência de uma lógica que articula o contexto do desencadeamento de uma neurose com a estrutura de quem sofre. Cabe ao analista fazer essa leitura, pois o desencadeamento revela algo do que na linguagem lacaniana se conhece como inconsistência daquilo que fazia a delimitação do gozo, levando o sujeito a interrogar sua posição. O surgimento de um sintoma, uma inibição ou um episódio de angústia seria uma forma de resposta, tentativa de solução para um problema inevitável e insuportável.

Estudiosos da psicanálise conhecem que há, em francês, dois termos usados por Lacan para se referir ao desencadeamento: o primeiro é déchainement, literalmente, desencadeamento, dado que chaine é cadeia; o segundo é déclenchement, que em espanhol tem a acepção de colocar em movimento e, em português, lançar-se. Esse uso intencional revela o desencadeamento como aquilo que ativa questões para o sujeito, ponto a partir do qual o sujeito é lançado na busca de respostas para seu desejo e, consequentemente, esvazia o valor patológico que se pode atribuir ao desencadeamento. 


\section{ARTIGOS}

Aqui, a ideia de temporalidade - sincronia e diacronia - se faz importante. É preciso tomar a diacronia para além de uma sucessão de acontecimentos fechados, isto é, como a razão que dirige essa sucessão: importam tanto os momentos de continuidade, como os de descontinuidade pela intrusão de algo que parece vir de "Outro lugar". É nesse sentido que é preciso destacar o valor semântico de desencadeamento como 'lançamento'. Ser lançado é mais que colocar-se em movimento, pois denota algo da ordem da intrusão. Quando Lacan (1973-74) chama alguns neuróticos de 'inabaláveis', ressalta que não há nada que os alcance nos efeitos provocados pela descontinuidade que provoca o sujeito a se 'lançar'.

Alguns autores tematizaram o momento do desencadeamento como coincidente com o pedido de uma análise. Dentre eles, Laurent (1995) que o vê "[...] equivalente ao reconhecimento de uma certa consistência inefável do gozo, que se oporia ao gozo calculável" (p. 11) e Leguil (1993), que se refere a ele como uma "[...] espécie de abalo no fantasma ou de separação entre sintoma e fantasma como algo que aparece no início e no fim de uma análise" (p. 25). Há também os que afirmam que nos momentos de desencadeamento acontece o encontro com o real, o sintoma vacila, há crise de gozo, formas de dizer que, de acordo com Dunker (2002), indicam a relevância clínica do problema do desencadeamento na neurose. Soma-se a isso, o fato cotidiano de analisantes dedicarem parte do tempo, no início de suas análises, ao que consideram a causa de seu sofrimento.

A partir dessas considerações, neste texto se percorrerá a noção de encadeamento e desencadeamento, nas formalizações de Freud e Lacan e o lugar do analista, em perspectiva contemporânea, ou seja, considerando o horizonte da época, com foco dirigido para as neuroses.

\section{Freud: dificuldades na economia libidinal, desencadeamento em cena}

Freud procurou, desde seus primeiros casos clínicos, estabelecer as circunstâncias e razões do adoecimento de seus pacientes neuróticos. Mesmo quando a tônica de seu trabalho não era a clínica, há referências ao tema do desencadeamento neurótico. Exemplo clássico está em "Moisés e o monoteísmo" (1939/1975), onde ele diz: "Trauma infantil - defesa - latência - desencadeamento da neurose - retorno parcial do recalcado: assim reza a fórmula que estabelecemos para o desenvolvimento da neurose" (p. 99). 
Em alguns de seus textos, Freud explicita a neurose como uma conjuntura psíquica que sobrevém para o sujeito, algo que lhe acontece sob determinadas condições, destacando, muitas vezes, que o indivíduo não é neurótico, mas torna-se neurótico. Temos aí, a ideia de que a partir de um ponto a neurose se 'manifesta' e o indivíduo cai doente. Destacam-se três de seus trabalhos, a seguir:

No texto "As neuropsicoses de defesa" (1894/1994a), Freud estabelece uma teoria da defesa, que o levou a considerá-la o núcleo do mecanismo psíquico das neuroses. Ao tratar da neurose obsessiva, em "Observações adicionais sobre as neuropsicoses de defesa" (1896/1994b), chama a fase de estabilidade localizada entre a neurose infantil e airrupção da neurose obsessiva propriamente dita, como "[...] período de aparente saúde, mas, na realidade, de defesa bem-sucedida" (p. 169). Nesse período há um processo de defesa que faz acalmar o conflito. O sucesso do mecanismo defensivo deixa como saldo o que ele chama "sintomas primários de defesa", modos de emudecer o desejo configurando-se com uma marca de rigidez e desconhecimento. Pode haver, entretanto, um momento em que algo reaviva o conflito, provocando o fracasso da defesa, colocando o sujeito na situação 360 da neurose propriamente dita, com o retorno das lembranças recalcadas. $\mathrm{O}$ desencadeamento acontece pelos diversos modos em que o sujeito é interpelado e se vê obrigado a dar uma resposta à realidade.

$\mathrm{Na}$ "Conferência XXIII: O caminho de formação dos sintomas" (1916/1976), Freud sustenta que a neurose é resultado de duas séries complementares, compostas por quatro termos: a primeira se compõe pela constituição sexual hereditária e uma vivência infantil; a segunda série é composta pela predisposição para a fixação libidinal e uma vivência traumática acidental no adulto. O primeiro termo, como lembra Dunker (2002), constituição sexual hereditária, define-se como uma predisposição à neurose, que remontaria à história da espécie, inaugurada pelo momento mítico e originário do processo civilizatório. Esta precondição seria reativada, retrospectivamente, pelo segundo termo, a vivência infantil, que se constitui por experiências organizadas em torno do tema da castração e ligadas ao complexo de Édipo. Introduz-se, então, o terceiro termo, a fixação libidinal, que funciona como efeito da associação das duas causas anteriores e como causa auxiliar na construção da neurose. Freud indica, aqui, o ponto de apoio para a fantasia, elemento que organiza as fantasias secundárias e os sintomas. Nos primeiros três elementos encontram-se as condições para a etiologia da neurose infantil e, portanto, para a formação de sintomas. Ele ainda acrescenta um quarto 


\section{ARTIGOS}

elemento, a vivência traumática, no adulto, como a causa desencadeante, geralmente associada à retomada da escolha de objeto. Liga essa causa a um estado intermediário entre a retirada da libido da fantasia e seu destino subsequente na formação dos sintomas. Considerava haver ou não formação de sintomas, que dependem da capacidade de resolução de aspecto quantitativo, fazendo menção à proporção, fração ou montante de libido e seu respectivo destino. Para Freud (1916/1976), a avaliação qualitativa dos determinantes etiológicos não é suficiente para a compreensão dos sintomas neuróticos, já que se pode supor que a "disposição de todos os seres humanos é semelhante e apenas difere em virtude dessas condições quantitativas" (p. 437). Pode-se concluir que a neurose aparece ou se desencadeia quando há um excesso de quantidade que excede a capacidade de resolução do sujeito.

Em "Tipos de desencadeamento da neurose" (1912/1974a), Freud se interroga sobre as condições necessárias para a irrupção de uma neurose, e estabelece quatro possibilidades dessa causa precipitante. Na primeira delas, um fator externo provoca uma frustração pela indisponibilidade do objeto real no mundo externo, com consequente introversão da libido que segue o caminho da regressão até o ponto de fixação, reinvestindo a fantasia e provocando a fuga para a neurose. A segunda forma de desencadeamento relaciona-se às dificuldades em se adaptar e responder às novas exigências da realidade, isto é, de trocar um tipo de satisfação por outra. Aqui, também há uma frustração, mas relacionada ao mundo interno, relacionada às aspirações do eu, ou seja, aos ideais. Um dos exemplos apresentados por Freud, é o caso do jovem que se satisfazia com a masturbação e não conseguia se aproximar do objeto de amor quando este se colocava como uma possibilidade real. O terceiro tipo diz respeito a uma inibição no desenvolvimento, localizada na passagem da infância à vida adulta. Trata-se de uma redução da possibilidade, antes tida como ilimitada, de fruição e de realização. No quarto caso, o desencadeamento liga-se a uma variação quantitativa de libido, mas de sentido inverso, no caso, um aumento, frequentemente ligada à puberdade. Trata-se da "[...] relação entre a cota de libido em operação e a cota de libido com que o ego individual é capaz de lidar — isto é, de manter sob tensão, sublimar ou empregar diretamente" (Freud, 1912/1974a, p. 297).

Constata-se, assim, na obra freudiana, que estas quatro formas de desencadeamento não se dão de forma pura, mas, frequentemente aparecem combinadas, com o predomínio de uma sobre as outras. O que elas trazem em comum é o fator quantitativo da libido, que será tanto mais patogênico quanto mais aumentado. É digno de nota ressaltar que Freud não ressalta diferença na 
quantidade de libido entre os sujeitos sãos e os neuróticos, ambos lutam para lidar com essa libido, mas os sãos foram os que se saíram melhor nessa tarefa.

Freud sempre associa o fator quantitativo e o fator libidinal como muito relevantes no desencadeamento. A esses dois fatores deve-se somar uma vivência traumática e acidental na vida adulta, de nenhum modo previsível. Estas são as bases sobre as quais sustentou sua teoria do desencadeamento, da neurose

\section{Lacan: dois modos de ler o desencadeamento}

No ensino lacaniano existem várias referências sobre o desencadeamento, especialmente aquelas relacionadas no Seminário Livro 3: as psicoses (1955-56/1988), e "De uma questão preliminar a todo tratamento possível da psicose" (1958/1998a), exemplares de seu ensino inicial, e às formalizações da topologia do nó borromeano, a partir do Seminário Livro 21: os não tolos erram (Lacan, 1973-74).

Nas primeiras referências, a leitura do desencadeamento se centra no 362 funcionamento psicótico. Nesses anos são estabelecidas três condições para esse desencadeamento: uma estrutural, que é a foraclusão do Nome-do-Pai, outra relativa à quebra das identificações imaginárias, e uma condição específica, o encontro com Um-pai. Na clínica borromeana Lacan estabeleceu o desencadeamento pelo desatamento dos nós, formalizando a importância do sinthoma, que se constitui como o elemento que repara os erros do enodamento e mantém o enlaçamento.

Schejtman (2013) esclarece que entre os anos de 1971 a 1973, Lacan estabelece que o desencadeamento se daria pelo corte ou ruptura de um dos elos construído entre R, S, I, e a consequente soltura dos outros dois; entre os anos de 1974 a 1976, o desencadeamento seria ocasionado pelo aparecimento de lapsos, ou erros, no nó. Dessa forma, Schejtman (2015) lê que o desencadeamento, na época da clínica borromeana, pode ocorrer de duas formas: pela cessação da função do sinthoma que deixa de funcionar, ou pelo aparecimento de um novo lapso na estrutura nodal. Ambas exigem nova reparação, isto é, uma nova estruturação do sinthoma.

Leibson (2012) considera que não se se deve pensar em psicogênese para a neurose, tal como Lacan assinalou no Seminário Livro 3. As psicoses (1955-56/1988), pois, em psicanálise não há psicogênese, ou seja, não se pode abordar o psíquico pela continuidade e unidade sustentadas numa relação de 


\section{ARTIGOS}

compreensão, como queria Jaspers. Nesse sentido, na neurose "[...] o que há é desencadeamento, ou seja, irrupção, corte, tropeço, desconcerto". O que vinha fixo, organizado, dá mostras de vacilação. Em seu lugar surge algo incômodo sob um traço de prazer, que é ignorado pelo sujeito e "[...] essa ignorância é decisiva no momento de formular uma pergunta. Porque é aí onde a 'saúde aparente' se revela ser na verdade bastante insalubre, e o sintoma surge como uma tentativa de cura" (p. 272; tradução nossa). Mesmo contando com a função do Nome-do-Pai, o sujeito neurótico, no contexto do desencadeamento, se descobre impedido de responder ao gozo a partir do que sabe.

Os estudiosos do tema notam que, nos anos 1970, a partir das formulações dos nós borromeanos, Lacan toma a psicose e a neurose como formas de respostas à não existência da relação sexual, isto é, ao fato de que a estrutura, em sua origem, é falha, necessita de uma reparação, de uma resposta. Tal resposta é tratada em termos de encadeamento, enlaçamento, desencadeamento e desenlace.

A partir do nó neurótico, borromeano, desenhado por Lacan (1974-75), de acordo com Leibson (2012), constata-se que "[...] toda estrutura é efeito de um enodamento que supre uma impossibilidade de encontro. O impossível da relação sexual que não há é o que sustenta e, por sua vez, enlaça o nó" (p. 273). Se é próprio da estrutura do ser falante a ocorrência de lapsos, de erros do enlaçamento, o desencadeamento, então, segue a mesma lógica do encadeamento e passa a não ser algo estranho à estrutura, um acontecimento anômalo. Ele permite a retomada da temporalidade, por meio da qual se revelam, na pergunta do sujeito, novos relevos e modulações que indicam os traços da resposta na própria pergunta. Nesse momento do ensino de Lacan, como foi visto anteriormente, o desencadeamento é ocasionado pela soltura dos elos do nó, provocada pela ruptura de um deles.

Nesse sentido, o desencadeamento pode ser visto como uma experiência de loucura, entendida como a perda do enodamento, que implica a dissolução do sujeito, muitas vezes com a perda do sentido e da unidade corporal. Nesse ponto, faz-se necessário destacar que a loucura e a psicose não se sobrepõem (Munõz, 2008), pois há formas de enlouquecimento que não são exclusivas da psicose, podendo ser encontradas nos neuróticos.

Surge, aí, a questão do louco como aquele que está deslocado em relação aos outros de sua comunidade e, especialmente, deslocado de si mesmo. Leibson (2012) ajuda aos interessados no tema, retomando os dois modos pelos quais Lacan fala de loucura. Segundo ele, o primeiro está relacionado aos desenvolvimentos de Hegel, nos quais a loucura é algo essencial 
do homem, está referenciada à estrutura do eu, suportada por um desconhecimento de sua falta constitutiva (Lacan, 1946/1998b). Assim, a loucura seria a crença no eu, na unidade do eu, envolvendo o desconhecimento de sua estrutura dependente do Outro e do outro, o que a faz essencialmente cindida. Crer no eu como completo, sem fissuras, é efeito do desconhecimento de que essa estrutura está sustentada por uma identificação ao outro, semelhante, e ao efeito da estrutura da linguagem, o que gera uma falta a ser originária, uma clivagem entre o simbólico e o real, que faz o sujeito ser dividido. Desconhecer essa divisão é o que Lacan considera a loucura essencial do homem.

O segundo modo de Lacan referir-se à loucura, surge a partir das operações com o nó borromeano, no Seminário 21. Ali, a loucura aparece como o efeito do rompimento de um dos registros ou elos do nó, e o consequente desenlaçamento. A loucura não é somente a dissolução do imaginário, mas do próprio nó, seja pela inoperância do sinthoma ou pela necessidade de uma nova reparação, como explica Schejtman (2013). Nesse sentido, a loucura coincide com o momento do desencadeamento, irrupção do diferente, na neurose ou na psicose.

364 Leibson (2012) adverte os estudiosos, no entanto, que loucura e desencadeamento não se recobrem totalmente, pois não são idênticos. Há loucuras que não tomam a forma de desencadeamento, pois também podem se apresentar como uma forma de rigidez subjetiva: "A loucura sempre vinculada ao desconhecimento da falta no Outro mediante certa idealização [...] se articula também com certos modos de encadeamentos caracterizados pela rigidez e estreiteza de movimentos subjetivos" (p. 281; tradução nossa). Pode-se tomar a rigidez e a ruptura como duas modalidades clínicas de loucura. Para o autor, embora não haja relação de verso e anverso, ou de simetria entre elas, a ruptura pode mostrar o que estava cristalizado como rigidez e suportava a tensão de uma pergunta ou de um conflito. Em razão disso, Leibson destaca que o desencadeamento e o encadeamento têm a estrutura de uma banda de Möebius.

Para ilustrar essa relação, vale que o leitor retome os paradigmáticos casos Dora (1905/1989) e O Homem dos Ratos (1909/1974b), nos quais a neurose é descrita a partir de sintomas, inibições ou angústias que funcionam, ora para estruturar e manter a ordem das coisas, de forma que o sujeito possa viver com sua neurose, ora como sintomas insuportáveis que tomam a forma de loucura, impelindo o sujeito ao tratamento. Não se pode esquecer que Lacan (1955-56/1988) afirma, seguindo indicação freudiana, que a neurose 


\section{ARTIGOS}

tem estrutura de pergunta e, assim, ao retomar a Freud, percebe-se que cada caso clínico consiste em, de um lado, localizar esta pergunta e, de outro, as respostas que possam estar incluídas na pergunta para articular o momento do desencadeamento.

Em "Fragmento de uma análise de um caso de histeria" (Freud, 1905/ 1989) vemos que, inicialmente, Dora era apenas uma histérica com seus sintomas não suficientes para que ela procurasse tratamento. Era o momento da histeria estabilizada, algo funcionava como uma sustentação de modo que Dora se mantivesse compensada.

Em Dora, o problema e a pergunta para Freud, diz respeito a como enfrentar o amor e a sexualidade a partir dos acontecimentos com o sr. K. Para Lacan, em sua releitura do caso, toda essa trama pode ser colocada sob a questão do que é ser uma mulher ou, de como Dora podia localizar-se em relação a esse mistério insondável da posição feminina e ao gozo ligado a essa posição.

Lacan (1955-56/1988) frisa que o quarteto formado por Dora, seu pai, a sra. e o sr. K fez a função de estabilização. O objeto de interesse de Dora era a sra. K, amante de seu pai. A afonia de Dora acontece quando o sr. K não está e ela fica sozinha na presença da sra. K, diante do enigma da feminilidade. Para Dora, a forma de abordar a feminilidade, em função da impotência do pai, é a oralidade traduzida pela felação e expressa no sintoma da tosse e da afonia. É assim que, diante das dificuldades de Dora para lidar com o reconhecimento de sua feminilidade, a identificação imaginária ao sr. K, que dava consistência ao seu eu, e o lugar da versão impotente do pai, organizada em torno da tosse, foi o que lhe permitiu abordar a outra mulher, e o que contribuiu para a sua estabilidade.

A cena do lago, em que o sr. $\mathrm{K}$ diz a Dora que sua mulher não era nada para ele, marca a ruptura formada pelo quarteto e é apontada, por Lacan, como o momento do desencadeamento da neurose. A fala do sr. K coloca para Dora a questão: "Então, o que você é para mim?". É digno de nota relembrar que o sr. K havia beijado Dora quando ela esteve em sua loja, aos 14 anos, mas esse acontecimento em nada modificou a relação entre os quatro personagens. Isso indica como a fala do sr. K é fundamental, já que era a sua mediação que permitia a Dora sustentar uma relação suportável com a sra K. A partir de sua fala, a solução apresentada pela identificação viril se desfaz, e o desencadeamento acontece marcado pela bofetada recebida pelo sr. K, como uma passagem ao ato, isto é, como uma ruptura com a continuidade. Como resultado, temos sua loucura, descrita por Lacan (1958/1998a), como 
“[...] uma pequena síndrome de perseguição tão-somente, que aparece em Dora com relação ao seu pai" (p. 109), experimentando um fenômeno interpretativo, até alucinatório, mas que não chega a produzir um delírio e nem se configurar numa paranoia.

É na posição reivindicativa e 'louca', que Freud recebe Dora, e lhe possibilita construir sua participação na acusação que fazia ao pai, possibilitando-lhe uma retificação subjetiva para deixar seu lugar do desconhecimento de seu gozo, construindo outra solução, ou seja, modo de organizar outro sinthoma. No caso Dora, de acordo com Schejtman (2013), a solução construída, anteriormente - o sinthoma —, deixa de funcionar, caduca, o nó vacila e sobrevém o desencadeamento na forma de loucura, em posição persecutória em relação ao seu pai.

Em "Notas sobre um caso de neurose obsessiva" (1909/1974b), ou O Homem dos ratos, como se conhece, Freud localiza o desencadeamento a partir do seu mito individual. Tal mito revela que o sujeito estava em uma conjuntura de escolha de objeto, que se estruturava sob os mesmos termos que a de seu pai, que pode ser traduzida como uma pergunta sobre a morte e a vida.

O primeiro episódio, ao qual Freud (1909/1974b) remonta o estabele366 cimento da neurose adulta do paciente, diz respeito à fala de um tio no velório de sua esposa, que exclama em tom queixoso: "outros maridos se permitem tudo, e eu vivi somente para esta mulher" (p. 179). O paciente supõe que o tio se referia ao seu pai. Sua fala coloca o sujeito confrontado com a dívida de amor do pai, pois mesmo não sendo infiel, o pai se casou com uma mulher rica e abandonou a sua amada pobre, casando-se por conveniência. Schejtman (2013) frisa que "[...] a falha do pai, vista nesse ponto, deixa lugar à resposta obsessiva: o sujeito se encarrega de des-culpar o Outro carregando sobre suas costas o peso do remorso" (p. 204; tradução nossa), já que Ernest se sentia culpado por não estar presente na morte do pai, a ponto de considerar-se um criminoso. Temos aqui que o sintoma é uma tentativa de tratar o que poderia ser um desencadeamento, pois por mais terrível que fosse o remorso, este exercia uma função sinthomática enlaçando a estrutura.

O segundo episódio se dá quando sua mãe lhe comunica o plano de fazê-lo se casar com a filha de um primo rico, logo que ele terminasse os estudos de Direito. Assim, ele deveria se decidir se ficaria com a mulher que amava ou se casaria com a mulher rica, nos moldes do que seu pai fizera. Ernst adoece, pois é confrontado, uma vez mais, com a dívida de amor do pai e, novamente, encontra na doença o tratamento para essa situação. Nesse caso de Freud, a inibição também tem uma função encadeadora, estabilizante: em 


\section{ARTIGOS}

face do conflito entre a sua escolha amorosa e o efeito continuado da vontade do pai, sobrevém uma inibição que o impede de estudar ou trabalhar, mas que o faz escapar do enfrentamento com seu desejo.

O terceiro episódio, uma série de acontecimentos ocorridos na época em que fazia serviços militares, provoca a ruptura de sua estabilidade e o leva a procurar tratamento com Freud. O encontro com o "Capitão Cruel" marca o início de seu tormento, pela narrativa da tortura com os ratos, com um tom de sadismo. As identificações paternas se reavivam e a fantasia se atualiza nos personagens da trama: 'Capitão Cruel' - com o relato do suplício dos ratos — Tenente 'A' e Tenente B a quem não podia pagar a dívida relativa aos seus óculos que chegaram pelo correio. Aqui o sujeito se vê confrontado com outra dívida paterna: a dívida do jogo. Seu pai havia sido um jogador que contraiu dívida, com um amigo, a quem tentou, depois, pagar e não conseguiu. Toda a fantasia obsessiva de Ernst se sustenta na ligação dos significantes Ratten (ratos) — Raten (prestações) - Verheiraten (casar) - Spielraten (rato de jogo, como o paciente define seu pai).

De acordo com Leibson (2012), com o desencadeamento a inibição dá lugar à angústia, como em Dora, mas com outra apresentação clínica: aqui o desencadeamento toma forma de loucura com delírios obsessivos. Estes colocam o Homem dos ratos em uma série de movimentos que anulam uns aos outros, com premissas falsamente verdadeiras que lançam o sujeito à obediência louca e cega de um Pai — do seu pai, na figura do Capitão Cruel - a quem não pôde contradizer.

Destaca-se, a partir desses casos, que a loucura coincide com o momento do desencadeamento, mas, apresenta-se também como uma posição desconectada dele, presente nos momentos anteriores, quando Dora e Ernest não se implicam naquilo que lhes faz sofrer. Tornar-se louco refere-se à perda da estabilidade da estrutura pela ruptura dos elos do nó, mas, como foi observado anteriormente, não se restringe à psicose: a loucura pode articular-se em qualquer estrutura clínica, segundo as formas da ruptura e da rigidez mencionadas.

\section{O Sinthoma, o sintoma e suas relações com o desencadeamento}

$\mathrm{Na}$ direção apontada, a discussão de como o sintoma e o sinthoma se articulam com o desencadeamento, na clínica borromeana, se faz necessária. 
Lacan apresenta, nessa época, algumas mudanças na concepção de sintoma que rompem com a noção de que ele seja metáfora, proposta na clínica estruturalista. A primeira delas é apresentada em A terceira (1974/2011), onde ele diz: "[...] chamo de sintoma ao que vem do real" (p. 17). Nesse caso, real como oposição ao discurso do mestre $\left(S_{1}-S_{2}\right)$, aquele que faz as coisas andarem ao passo de todo mundo. Trata-se do que se põe em cruz, repetidamente, atrapalhando o andar. No Seminário livro 22: RSI (Lacan, 1974-75), ele é apresentado juntamente com a inibição e a angústia, como uma das três nominações, R, S, I, - isto é, o quarto elo que encadeia e enlaça o nó - como aquilo que não anda bem no real, pelos efeitos da intrusão do simbólico sobre esse registro. Percebe-se, então, uma mudança radical na perspectiva do sintoma, antes ligado à substituição significante e à metáfora.

A noção de sinthoma, por sua vez, foi apresentada por Lacan (1975-76/2007, pp. 90-91) não apenas como um quarto elemento que promove o encadeamento dos registros, mas considerado como o elo que faz a reparação dos erros no enlaçamento. Ele mantém os registros do real, do imaginário e do simbólico enlaçados, promovendo a estabilidade do nó, e, logo, do sujeito. O 368 sinthoma, como ressalta Schejtman (2013), está lá em todo o tempo anterior ao desencadeamento e, portanto, não deve ser reduzido ao resultado do final de uma análise ou à vertente real do sintoma, como defendem alguns teóricos. Tanto o sintoma, quanto a inibição e a angústia, podem fazer função de sinthoma, como se viu nos casos Dora e O homem dos Ratos, pois, como nominações equivalentes na sua função, enlaçam e estabilizam. Assim, o sinthoma é índice de estabilidade, de estrutura encadeada.

Schejtman (2013) destaca que há uma forma geral de apreensão do conceito de sintoma, que pode ser caracterizada por uma forma de sofrimento e, inclusive, aparecer como inibição ou angústia, que pode ser tomada como índice de desencadeamento, como forma de loucura, tal como a posição reivindicativa e persecutória de Dora ou as obsessões do Homem dos Ratos. Segundo ele, um mesmo sintoma, como a anorexia, por exemplo, pode funcionar para diferentes sujeitos como sintoma ou como sinthoma, dependendo das contingências da vida, e aborda os casos Marina, Júlia e Mariano, exemplificando tais funções.

O caso Marina se refere a uma jovem psicótica para quem a anorexia funciona como uma defesa diante das sensações da menarca e da ideia delirante de que a sua mãe queria solidificá-la. Apesar de a anorexia colocar em risco a sua vida, a restrição alimentar e a redução de sua dieta a puro 
líquido “[...] tem uma função precisa na estrutura: forma parte de uma solução, de modo que neste caso se mantém estabilizada uma estrutura psicótica [...], isto é, tem função de sinthoma" (Schejtman, 2013, p. 286; tradução nossa). Estabilização que poderia levá-la à morte, ou seja, o sinthoma nem sempre evita o sofrimento ou coloca o sujeito a salvo.

No segundo caso, trata-se de uma adolescente neurótica de 16 anos, para quem a anorexia é a marca do desencadeamento de sua histeria. Ela era uma 'gordinha feliz' que passa a se impor restrições alimentares ao não suportar ver seu corpo no espelho na época em que começa a manter relações sexuais com seu namorado. A anorexia aqui é sinal de que um problema foi iniciado, indicando que algo deixou de funcionar bem, ela já não é mais a 'gordinha feliz', configurando-se como um sintoma.

O terceiro caso, um adolescente de 14 anos supõe uma psicose ordinária. Mariano passa de uma posição de gordo feliz e respeitado pelos amigos, para uma posição anoréxica iniciada a partir do encontro com seu pai, separado de sua mãe, que o visita no hospital e lhe leva um pedaço do bolo do primeiro aniversário de seu irmãozinho. Com a análise o paciente experimenta uma melhora de seu estado, de modo a retomar a sua vida. A sua relação com a comida, entretanto, permanece como ponto importante, pois passa a comer compulsivamente e desenvolve um quadro de bulimia. Assim, segundo Schejtman, ele passa de uma estrutura enlaçada, entre R, S, I, e estabilizada pelo nome "Mariano, o gordo", para uma posição anoréxica, a partir do encontro com Um pai (Lacan, 1958/1998a), essencial nos desencadeamentos psicóticos. No caso, é o próprio pai que ao noticiar o nascimento do irmão, quem aponta um buraco na estrutura e provoca o desencadeamento. A anorexia, aqui, não tem função de reparação sinthomática, pois “[...] é efeito mesmo do desencadeamento, efeito disruptivo da foraclusão do Nome-do-pai recentemente vista: sintoma" (Schejtman, 2013, p. 301; tradução nossa). Assim, neste caso, a anorexia e a bulimia têm função de sintoma pois trazem a marca do desencadeamento.

A partir desses casos, Schejtman (2013) destaca que é muito importante diferenciar a noção de estabilidade, promovida pelo sinthoma, do desencadeamento explicitado pelo sintoma para a orientação e intervenção analítica. A partir dessa localização, o analista poderá decidir se aposta colocar em questão a solução sinthomática que o sujeito encontrou, especialmente, quando se tratar de uma neurose.

Isso implica conceber que nem tudo o que se apresenta clinicamente como crise subjetiva corresponde, necessariamente, ao desencadeamento 
da estrutura em termos nodais. Há de se considerar a possibilidade de que fenômenos clínicos diversos, que usualmente são tomados como momentos subjetivos críticos, desestabilizações e descompensações várias ou, até mesmo, angústias que se estendem no tempo, por mais críticos e problemáticos que pareçam, podem supor, na estrutura, certa rigidez de enlaçamento. Nesse sentido, é necessário supor que muitos adoecimentos ou sofrimentos, especialmente na atualidade, podem trazer a marca de um não desencadeamento e, portanto, o analista necessita identificar se o que se apresenta, aparentemente, como sintoma, não se trata de sinthoma.

Assim, é digno de nota relembrar uma passagem em que Schejtman (2018) argumenta que o sinthoma, por dar estabilidade, não indica ausência de sofrimento já que, como afirmou Lacan: “[...] o sinthoma é sofrer por ter uma alma" (p. 709; tradução nossa). Se é assim, eventualmente, uma psicanálise pode pôr em questão essa rigidez, já que ao sustentar a etimologia de 'análise', que significa desatar, o analista engendra a possibilidade de articular-se, ali, uma pergunta que abale a estabilidade do sujeito.

\section{$370 \quad 0$ analista diante do não desencadeamento neurótico}

As questões colocadas até aqui, têm valor na atualidade, pois as neuroses têm se reorganizado, em sua apresentação, a partir da incidência do discurso capitalista que potencializa o imperativo de gozar, e o sujeito, pela disposição infinita de objetos consumíveis, muitas vezes ocupa o lugar do cliente que tem sempre razão. Como consequência, o estabelecimento de um sintoma analítico não se faz, dada a refratariedade ao inconsciente e, logo, a impossibilidade transferencial.

No prefácio à edição inglesa do Seminário 11 (1976/2003), Lacan afirmou que "[...] quando ... o espaço de um lapso — já não tem nenhum impacto de sentido (ou interpretação), só então temos certeza de estar no inconsciente" (p. 571). O que quer dizer o inconsciente aqui? Que ele não é mais concebido como estruturado a partir dos significantes $\mathrm{S}_{1}-\mathrm{S}_{2}$ e, logo, apreendido em torno de um sentido recalcado a ser desvendado. $\mathrm{O}$ inconsciente está sustentado pelo signo, pelo fora do sentido e pelo gozo, está mais próximo do real. As consequências clínicas dessa nova concepção dão

[...] lugar a uma abordagem mais ordinária da clínica, tanto no campo das psicoses como no das neuroses, tornando perceptível uma variedade de 


\section{ARTIGOS}

soluções inéditas com as quais, pelo uso do sinthoma, pode-se prescindir do pai, seja para além dele (no caso das neuroses) ou aquém (no caso das psicoses). (Souto, 2017, p. 22)

Essa clínica ordinária, portanto, trata de acolher aqueles padecimentos nos quais não houve um desencadeamento indicado pela ausência de uma pergunta, ou quando não há uma suposição de saber e de endereçamento ao Outro. Tais características marcam, de modo significativo, as subjetividades contemporâneas e coloca, no centro da clínica, questões éticas para o analista. Se a psicanálise tem alguma possibilidade, é porque algo desencadeou na vida de alguém e uma demanda é dirigida ao analista, como aprendemos com Freud. Observa-se, entretanto, que na atualidade a marca do não desencadeamento é evidente, "[...] a grande maioria das pessoas não precisa consultar o psicanalista: a compensação, a estabilidade é a regra. $\mathrm{O}$ desencadeamento franco é exceção. O ser humano médio se mantém ... dormindo" (Schejtman, 2015, p. 163; tradução nossa). A partir dessa indicação coloca-se a questão: qual a função do analista diante desses neuróticos?

Miller (2014) indicou que a desmontagem da defesa contra o real deve estar no centro da clínica do século XXI. E sua afirmação deriva das constatações lacanianas que, em 11 de janeiro de 1977, já havia usado a expressão 'perturbar a defesa', como forma do analista romper com o inconsciente que fala sozinho, o inconsciente autístico: durante a experiência analítica, ao dialogar com um psicanalista, a defesa inconsciente de cada sujeito deve ser visada, tocada, perturbada pelo analista. Perturbar a defesa não é incomodar a satisfação, mas os modos como ela se dá. Se a defesa, tomada aqui como sinthoma, deve ser perturbada e desmontada, nessa direção a análise deve se orientar no sentido de fazer desencadear, fazer sintoma.

O analista, entretanto, não deve se eximir de sempre julgar a conveniência, ou não, de colocar em questão a defesa sinthomática do sujeito. Não se deve perturbar a defesa nem liberar o sinthoma a qualquer preço. Nessa direção, convém relembrar que Lacan (1975-76/2007, p. 131) diz que o analista é um sinthoma e, nesse sentido, está no lugar de enlaçar. É sempre importante, portanto, destacar: há defesas a perturbar, a desmontar e novas defesas a construir.

Como se pode concluir, perturbar a defesa é o que faz abalar o modo autístico de satisfazer a pulsão, que o discurso capitalista, articulado com o da ciência, trata de servir e sustentar. Miller (1996/1999, p. 19) sublinha que o real é aquilo que surpreende, pois é da ordem do traumático. Espera-se, contudo, que o analista, por suas intervenções, e aqui deve-se destacar, ao 
perturbar e desmontar a defesa, possa surpreender o real. Trata-se do analista surpreendedor: se o desencadeamento neurótico, como a formulação de uma pergunta sobre o desejo e o gozo, como o momento de um lançar-se em questões, não parece ser regra, é imprescindível que o analista faça a leitura do que sustenta esse adormecimento do sujeito.

\section{Referências}

Dunker, C. I. L. (2002). O cálculo neurótico do gozo. São Paulo, SP: Escuta.

Freud, S. (1974a). Tipos de desencadeamento da neurose. In Edição Standard Brasileira das Obras Psicológicas Completas de Sigmund Freud (Vol. 12, pp. 289-299). Rio de Janeiro, RJ: Imago. (Trabalho original publicado em 1912).

Freud, S. (1974b). Notas sobre um caso de neurose obsessiva. In Edição Standard Brasileira das Obras Psicológicas Completas de Sigmund Freud (Vol. 10, pp. 157-252). Rio de Janeiro, RJ: Imago. (Trabalho original publicado em 1909).

Freud, S. (1975). Moisés e o monoteísmo. In Edição Standard Brasileira das Obras Psicológicas Completas de Sigmund Freud (Vol. 23, pp. 13-161). Rio de Janeiro, RJ: Imago. (Trabalho original publicado em 1939).

Freud, S. (1976). Conferência XXIII: O caminho de formação dos sintomas. In Edição Standard Brasileira das Obras Psicológicas Completas de Sigmund Freud (Vol. 16, pp. 419-439). Rio de Janeiro, RJ: Imago, 1976. (Trabalho original publicado em 1916).

Freud, S. (1989). Fragmento de uma análise de um caso de histeria. In Edição Standard Brasileira das Obras Psicológicas Completas de Sigmund Freud (Vol. 7, pp. 12-115). Rio de Janeiro, RJ: Imago. (Trabalho original publicado em 1905).

Freud, S. (1994a). As neuropsicoses de defesa. In Edição Standard Brasileira das Obras Psicológicas Completas de Sigmund Freud (Vol. 3, pp. 51-72). Rio de Janeiro, RJ: Imago. (Trabalho original publicado em 1894).

Freud, S. (1994b). Observações adicionais sobre as neuropsicoses de defesa. In Edição Standard Brasileira das Obras Psicológicas Completas de Sigmund Freud (Vol. 3, pp. 159-183). Rio de Janeiro, RJ: Imago. (Trabalho original publicado em 1896).

Lacan, J. (1973-74). Séminaire 21: Les non-dupes errent. Disponível em: <http:// staferla.free.fr/S21/S21.htm. $>$. Inédito.

Lacan, J. (1974-75). Le séminaire. Livre 22. RSI. Disponível em: <http://staferla.free. $\mathrm{fr} / \mathrm{S} 22 / \mathrm{S} 22 . \mathrm{htm}>$. Inédito. 


\section{ARTIGOS}

Lacan, J. (1988). O seminário. Livro 3. As psicoses. Rio de Janeiro, RJ: Jorge Zahar. (Trabalho original publicado em 1955-56).

Lacan, J. (1998a). De uma questão preliminar a todo tratamento possível das psicoses. In Escritos (pp. 537-590). Rio de Janeiro, RJ: Jorge Zahar. (Trabalho original publicado 1958).

Lacan, J. (1998b). Formulações sobre a causalidade psíquica. In Escritos (pp. 153-194). Rio de Janeiro, RJ: Jorge Zahar. (Trabalho original publicado em 1946).

Lacan, J. (2003). Prefácio à edição inglesa do Seminário 11. In Outros escritos. Rio de Janeiro, RJ: Jorge Zahar. (Trabalho original publicado em 1976).

Lacan, J. (2007). O seminário. Livro 23. O sinthoma. Rio de Janeiro, RJ: Jorge Zahar. (Trabalho original publicado em 1975-76).

Lacan, J. (2011, dez.). A terceira. (pp. 11-35). Opção Lacaniana, 62. (Trabalho original publicado em 1974).

Laurent, E. (1995, abril). As entradas em análise. Opção lacaniana, 12.

Leibson, L. (2012). Desencadenamientos y locuras en la neurosis (pp. 269-294). In F. Schejtman (Org.), Elaboraciones lacaniana sobre la neurosis. Buenos Aires, AR: Grama Ediciones.

Leguil, F. (1993). A entrada em análise e sua articulação com a saída. Fórum Inciativa Escola, Bahia.

Miller, J. A. et al. (1999). El conciliábulo de Angers (pp. 15-193). In Los inclasificables de la clínica psicoanalítica. Buenos Aires, AR: Paidós. (Trabalho original publicado em 1996).

Miller, J. A. et al. (1999). La conversación de Arcachon (pp.197-414). In Los inclasificables de la clínica psicoanalítica. Buenos Aires, AR: Paidós. (Trabalho original publicado em 1997).

Miller, J. A. et al. (2012). A convenção de Antibes. In M. C. D. Batista, \& S. Laia (Orgs.), A psicose ordinária. Belo Horizonte, MG: Scripitum. (Trabalho original publicado em 1998).

Miller, J. A. (2014). Apresentação do tema do IX Congresso da AMP. Disponível em: $<$ http://www.congresamp2014.com/pt/template.php?file=Textos/Presentation-dutheme_Jacques-Alain-Miller.html>.

Muñoz, P. D. (2008). El concepto de locura en la obra de Jacques Lacan (pp. 87-98). Anuario de Investigaciones, vol. 15, Universidad de Buenos Aires, Argentina

Schejtman, F. (2013). Sinthome, ensayos de clínica psicoanalítica nodal. Olivos, AR: Grama Ediciones.

Schejtman, F. (2015). Neurosis polisinthomadas o polireparadas (pp. 295-365). In N. Dafunchio, Ni neurosis, ni psicosis. Buenos Aires, AR: Del Bucle. 
Schejtman, F. (2018). Interpretación: perturbar la defensa, liberar el sinthome (pp. 708-709). X Congreso Internacional de Investigación y Práctica Profesional en Psicología XXV Jornadas de Investigación XIV Encuentro de Investigadores en Psicología del MERCOSUR. Facultad de Psicología - Universidad de Buenos Aires, Buenos Aires.

Souto, S. (2017). Descontinuidade do Édipo continuidade do gozo (pp. 20-22). Rumo à Barcelona 2018: as psicoses ordinárias, e as outras, sob transferência. Papers n. 3. Recuperado em 15 dez. 2018 de: <https://congresoamp2018.com/wp-content/ uploads/2017/12/PAPERS-7.7.7.N\%C2\%B03-Portugais.pdf>.

\section{Resumos}

(The concept of triggering in neurosis and its relationship with the sinthome and the role of the psychoanalyst in the context of current clinical psychology)

This article addresses the concept of triggering in neurosis by taking into account current clinical psychology and based on the concepts of chaining and triggering, according to Freudian and Lacanian teachings. Formalizations about the sinthome as an element that repairs bonding mistakes and the chaining index, and the sinthome itself, are convened for a conversation in which neurosis, even in the context of clinical psychology, often presents itself in its non-triggered form. The role of the psychoanalyst as a disrupter of both defense and the sinthome is therefore a question that arises in this scenario.

Key words: Triggering, neurosis, sinthome, psychoanalyst

(Le concept de déclenchement dans la névrose et son rapport avec le sinthome et le rôle du psychanalyste dans le contexte de la psychologie clinique actuelle)

Cette étude examine la notion de déclenchement dans la névrose en prenant pour base la psychologie clinique actuelle ainsi que les concepts de chaînage et de déclenchement selon les enseignements freudiens et lacaniens. Les formalisations sur le sinthome, en tant qu'élément qui répare les erreurs de liaison et de l'index de chaînage, ainsi que le sinthome, sont convoqués à la conversation dans laquelle la névrose, même dans le contexte de la psychologie clinique, se présente souvent sous sa forme non-déclenchée. Le rôle du psychanalyste en tant que perturbateur de la défense et du sinthome représente donc une question qui se met en évidence.

Mots clés: Déclenchement, névrose, sinthome, psychanalyste 


\section{ARTIGOS}

(El concepto de desencadenamiento en la neurosis y su relación con el sinthome y el papel del psicoanalista en el contexto de la psicología clínica actual)

Este trabajo aborda el concepto de desencadenamiento en las neurosis, considerando la práctica clínica actual y, para ello, transita por los conceptos de encadenamiento y desencadenamiento, basándose en las enseñanzas freudianas y lacanianas. Las formalizaciones sobre el sinthome, como un elemento que repara los errores de cruce y el índice de encadenamiento, y el síntoma en sí, son convocados a la charla en la que la neurosis, incluso en el contexto de la práctica clínica, se presenta a menudo en su forma no desencadenada. El papel del psicoanalista como perturbador, tanto de la defensa como del sinthome es, por lo tanto, una cuestión que surge en la escena.

Palabras clave: Desencadenamiento, neurosis, sinthome, psicoanalista

Citação/Citation: Silva, L. A. \& Ilka, F. F. (2021, junho). Desencadeamento na neurose e sua relação com o sinthoma e a função do analista no contexto da clínica na atualidade. Revista Latinoamericana de Psicopatologia Fundamental, 24(2), 356-376. http://dx.doi. org/10.1590/1415-4714.2021v24n2p356.8.

Editora/Editor: Profa. Dra. Ana Maria G. R.Oda

Submetido/Submitted: 21.5.2020 / 5.21.2020 Aceito/Acepted: 21.12.2020 / 12.21.2020

Copyright: (C) 2009 Associação Universitária de Pesquisa em Psicopatologia Fundamental/ University Association for Research in Fundamental Psychopathology. Este é um artigo de livre acesso, que permite uso irrestrito, distribuição e reprodução em qualquer meio, desde que o autor e a fonte sejam citados / This is an open-access article, which permits unrestricted use, distribution, and reproduction in any medium, provided the original authors and sources are credited.

Financiamento/Funding: Este trabalho não recebeu apoio / This work received no funding.

Conflito de interesses/Conflict of interest: As autoras declaram que não há conflito de interesses. / The authors declare that there is no conflict of interest. 


\section{Luciene Aparecida SiLVA}

Mestre em Psicologia pela Pontifícia Universidade Católica de Minas Gerais - PUC-Minas (Belo Horizonte, MG, Br); Especialista em Teoria Psicanalítica pela Universidade Federal de Minas Gerais - UFMG (Belo Horizonte, MG, Br); Psicóloga e supervisora do Centro de Atenção Diária e Integral em Saúde Mental do Ipsemg (Belo Horizonte, MG, Br).

Rua Fernandes Tourinho 735, sala 705 - Lourdes

30112-011 Belo Horizonte, MG, BR

silva_luciene@hotmail.com

https://orcid.org/0000-0003-4026-1101

\section{ILKa Franco Ferrari}

Doutora em Psicologia pelo Programa de Clínica y Aplicaciones del Psicoanálisis, na Universidade de Barcelona, Espanha; Professora Adjunto IV da Pontifícia Universidade Católica de Minas Gerais - PUC-Minas (Belo Horizonte, MG, Br).

Rua Itaú, 525 - Dom Cabral 30535-012 Belo Horizonte, MG, Br. francoferrari@terra.com.br/ ilka@pucminas.br https://orcid.org/0000-0002-6367-3136

This is an open-access article, which permits unrestricted use, distribution, the original authors and sources are credited. 